\title{
On Biodiversity of Xishuangbánna and its Conservation
}

\author{
LONG CHUNLIN \\ Kunming Institute of Botany, Academia Sinica, Kunming 650204, China \\ (Received March 18. 1994)
}

\section{ABSTRACT}

There lives a vast number of plant and animal species in Xishuangbanna. Biodiversity plays a significant role based on its function in economy, society, culture, religion, environment and germplasm conservation in Xishuangbanna prefecture. However, the environment for organisms is worsening and many species are on the brink of extinction. More than 200 species of organisms are believed to be in rare, endangered and near endangered status around the prefecture.

The preserving systems for organisms of Xishuangbanna can be divided into 3 subsystems: 1 ) national nature sanctuary; 2) traditional preserving system; and 3) conservation in scientific institution. Some new methods to preserve biodiversity such as: 1) international nature sanctuaries, 2) conservation in public yards and in agroforestry, and 3) traditional conservation systems (Holy Hills of Dai, Sangpabawa of Hani, tea garden of Jinuo, Buddhist temples and homegardens) are suggested in the present paper. Also the author proposes some strategies to preserve biodiversity (eg. help the residents in and near the nature sanctuaries, replace timber with bamboo, spread traditional artificial fuelwood forest techniques and stress local participation) based on the ethnoecological and human ecological viewpoints.

Key words biodiversity, conservation, traditional preserving system. Xishuangbanna

\section{Introduction}

Xishuangbanna, a Dai Autonomous Prefecture in Yunnan tropics, SW China, stretches through $19223 \mathrm{Km}^{2}$. It is taken specific note for its special geographical location and natural conditions. Among its indigenous endowments (such as minerals, solar energy, water energy, abundant rainfall), organisms are the most essential resources for mankind. It is regarded as the richest area in both the number of species and ecosystem types in China.

The vegetation in Xishuangbanna consists of two major groups: tropical evergreen forests in the mountain areas and tropical monsoon forests in the valleys and hilly areas. Also rainforest, bamboo forest, conifer and broadleaf mixed forest, shrub, and grassland are common vegetation types in Xishuangbanna.

People of Xishuangbanna, though they have been living on relatively primitive agriculture, have changed the environment for human beings as well as organisms. On the other hand, biodiversity of Xishuangbanna has affected the socio-economic and cultural conditions and given endowments to human. This relationshop has existed since human came to this region.

According to the census of 1982, the total population of Xishuangbanna was 646 
449. In addition to Han Chinese (the major nationality in China), they also consist of Dai, Hani, Yao, Miao, Lahu, Bulang, Yi, Jinuo, Wa, Hui, Bai, Zhuang, Buyi and other small ethnic groups in the mountains. Dai is the largest nationality in the region and comprises $34.87 \%$ of the total poputation.

\section{On the biodiversity of Xishuangbanna}

\section{1 General description}

Special location, varied landforms and diversified climates create an appropriate environment for the organisms of Xishuangbanna. More than 4500 species and varieties of higher plants have been found. Among these plants, there are some 1100 species being used nowadays for industry, daily life and other purposes. The major source of commercial plant products includes 13 groups (Table 1 ).

Table 1 The major commercial plant resources of Xishuangbanna.

\begin{tabular}{lll}
\hline Group & Species & Representatives \\
\hline wood & 200 & Anthocephalus chinensis \\
oil & 150 & Hodgsonia macrocarpa \\
perfume & 250 & Cinnamomum yunnanensis \\
medicine & 920 & Homalomena oculta \\
fruit & 170 & Magifera indica, Musa spp. \\
ornament & 200 & Thunbergia coccinea \\
forage & 250 & Paspalum distichum \\
tanning & 60 & Phyllanthus emblica \\
dye & $>10$ & Baphicacathus cusia \\
starch & 250 & Amorphophallus yuloensis \\
gum & $>33$ & Garcinia xishuangbannaensis \\
fiber & 90 & Sterculia spp.. Tilia spp. \\
rattan & $>15$ & Calamus spp. \\
\hline
\end{tabular}

It is still unknown that how many species of animals are there in Xishuangbanna. Most of the animals belong to the invertebrates (eg. butterflies, spiders). However, Xishuangbanna is still the richest region for vertebrates in China. Among 758 vertebrate species, fish, birds and mammals are the main groups (Table 2).

Table 2 The verberates of Xishuangbanna, China.

\begin{tabular}{lccccl}
\hline Group & Order & Family & Genus & Spp. & Representatioves \\
\hline Fish & & 18 & 54 & 100 & Kryptopterus moorei, Labeoninae yunnanensis \\
Amphibian & 3 & 7 & 15 & 47 & Ichthyopterus hannanica, Platymanis liui \\
Reptile & 3 & 15 & 41 & 74 & Varanus salvator, Python molurus bivittatus \\
Bird & 18 & 51 & & 429 & Pavo muticus imperator, Gallus gallus spadiceus \\
Mammal & 9 & 32 & 74 & 108 & Viverra zibetha surdaster, Elephas maximus indicus \\
\hline
\end{tabular}

2. 2 Importance of biodiversity in Xishuangbanna

2. 2. 1 Economics

People living in the tropical areas could receive much more benefit from diversified organisms nearby. For instance, Dai people who reside in basins collect usually less non-forest products while residents in mountain areas can receive much more endowment form națural forests because of diversified resources close at hand. Hani people who live in the Mengsong Mountains collect 120 spp. plants for food, medicine and other purpos- 
es, and for cash (Xu, 1991).

\section{2. 2 Society, culture and religion}

In accordance with the principle of ethnobiology, there are systematic relations between humans and bio-resources. That is, human beings can have impacts on Bio-organism and can experience impacts from other organisms. Human behavior, consciousness. culture, beliefs, society and other activities for production reflect the biotic world around humans after they have lived in the bio-environment for generations. People who live in the areas of high biodiversity possess much more knowledge about organisms and the environment. They understand how to use (collect, introduce and acclimatize) all kinds of the wild species nearby.

Abundant indigenous knowledge about organisms is an important component of society and culture in Xishuangbanna. Many words, poems, dances, songs, stories and legends of traditional knowledge about organisms have been handed down from generation to generation and now they are still be used to tell villagers about the origin, characters and uses of organisms as well as how to preserve them and their environment.

Worship of plant and animal totems indicates the relationship between indigenous religion and the environment. The famous example is Buddhism and forest in Thailand (Wechakit, 1989). Buddhist villagers as well as monks plant, manage, conserve and use trees (and wildlife). The same phenomenon exists in Xishuangbanna's Dai society and other minority societies such as Bulang and Lahu.

\subsubsection{Environment}

The ecosystem with diverse organisms will be stable and sustainable. In a complex ecosystem. different bio-species occupy different niches of the system and there are complex relations among these organisms. When a certain link among organisms is injured, it can be compensated if there are many bio-species in the system, and the system will remain stable. As an important emergent property of the environment, biodiversity performs certain functions including purifying water and air, and adjusting the micro-climate. Erosion is regarded as one of the gravest problems environmentally around the world, especially in the tropics like Xishuangbanna. Vegetation which consists of diversified organisms can prevent erosion.

\section{2. 4 Gene pool}

Southeast Asia is one of the megagene centers of agriculture in the world. Many important economic crops (eg. bananas, oranges, areca, jackfruit, mango, coconut, ginger, tea, pepper, bamboos, teak, some varieties of rice and sugar cane) and a great number of famous and precious animals such as Indian elephant, rhinoceros, crocodile, peacock, parrots, hornbill, golden pheasant and some insects originated from Southeast Asia. Xishuangbanna is one of the key regions of Southeast Asia for its unique location and climate. The ancestors or relatives of about 100 species and varieties of cultivated plants are found in Xishuangbanna ( $\mathrm{Xu}$ et al., 1982). These important plants include: Oryza meyeniana, Coix lacryma-jobi, Litch chinese var. spontarius, Nephelium cryseum. Cucumis yunnanensis, Momordica charahtia, Piper longum, Amomum villosum var. xanthioides. Magifera indica, Musa spp., Canariumalbum, Canarium tokinensis, Choerospondias axillaris, Panax pseudogensen var. japonica. Amorphophallus spp.. Homalomena oculta and Dendrocalamus spp. These plants together with other wild plants compose a vast reservoir of germplasm. They are economically and theoretically impor- 
tant to the study of the origins of cultivated plants as will as in the breeding of new improved varieties.

The yard of Xishuangbanna is another significant gene reservoir. For instance, more than 13 varieties of mango (Mangifera indica) are found in Dai gardens. Banana (Musa sapientum) also exists in several varietal forms. They could be useful in breeding improved varieties of crops (Long, 1990)

Xishuangbanna is the distribution center of primates and the civet family animals of China (Liu, et al., 1990). Many other animal species, including butterflies and reptiles, also concentrate in this region. Therefore, Xishuangbanna may be considered as an animal gene center also.

2. 3 The status and problems of biodiversity in Xishuangbanna

Xishuangbanna was known as "the Bright Pearl in the Kingdom of Plants and Animals" for its abundance in plant and animal species in Yunnan, even in China. However, the natural vegetation has been heavily destroyed and the forest coverage has deceased from $60 \%$ to $30 \%$ in 40 years. The species in this region, like other parts of the world, is rapidly reducing since the bio-environment has been destroyed. Some species are regarded as rare, endangered or near endangered.

Scientists warned that there lives 31 species of so-called living-fossil plants, 153 endemic plant species and 132 rare plant species in Xishuangbanna. The Chinese government has designated 37 animal species living in Xishuangbanna for preservation since 1983 because the animals (such as golden pheasant, peacock and elephant) are nearly extinct from the region.

Weeds are an important factor in preventing the reestablishment of natural vegetation in Xishuangbanna. Three weeds, Eupatorium coelesticus, E. odoratum and Tithenia diversifolia, which all belong to the Compositae family, invade the fallow field between forest, shifting fields and even the secondary forest. They grow and reproduce very quickly and can stop other plants from becoming established.

\section{Conservation of biodiversity}

\section{1 Preserving systems in Xishuangbanna}

The usual organization of preserving bio-resources refers to governmental agencies and specific scientific institutions such as botanical gardens, nature sanctuaries and zoos. However, traditional or indigenous conservation systems play an improtant role in Xishuangbanna. The Holy Hills of Dai. Sangpabawa of Hani and other bio-conserving systems have been proved to be effective and sustainable.

\subsection{National nature sanctuaries}

Five national nature sanctuaries have been established in Xishuangbanna prefecture over a dozen years. "They are located in Mangao, Mengyang, Menglun. Mengla and Shangyong respectively. The total area is 200000 hectares and the forest coverage has reached $89 \%$. Almost all the organisms of Xishuangbanna can be found in the sanctuaries. This system is absolutely the most important to conserve biodiversity. But there are many problems (eg. people living in and near sanctuaries, acceptable law or regulations, exploitation) to manage and perfect this preservation system.

3. 1. 2 Traditional conservation systems 
Traditional or indigenous conservation systems were created by local or native people for the sake of economy and religion. These systems have been adopted and handed down over a long time in Xishuangbanna and have proven to be effective and acceptable to conserve biodivêrsity. They are composed of many components such as the Holy Hill of the Dai (Pei, 1985a, 1986; Liu 1990). Sangpabawa (traditional preserving forest) of the Hani ( $\mathrm{Xu}, 1991$ ), Buddhist temples (Pei, 1985a), yards (Long, 1990), and tea plantation of Jinuo (Long et al., 1993). These systems will be described in detail in the next part.

\section{1. 3 Scientific institutions}

Some plants and animals are introduced into scientific institutions in Xishuangbanna prefecture on a small scale for scientific studies and other purposes. Meanwhile they can be conserved and managed.

\section{2 Methods}

The goal of all of these is to conserve biodiversity or bio-resources ( $\mathrm{Xu}$ et al. , 1982; Lu, 1987). The common preservation methods refer to two aspects: in-situ and $e x$-situ. Although a lot of suggestions and comments have been suggested, almost all of them focus on how to conserve in-situ and ex-situ. The following opinions are relatively new and differ from common ones:

\section{2. 1 Conservatio in-situ-international nature sanctuaries}

Preserving biodiversity should be boundary-less even though the bio-resources may be divided by national boundaries. That is, conservation of organisms can only be achieved on a global level since plants can disperse their seeds (or fruits) from one country to another and animals can move themselves to other territories. Therefore, it is necessary to establish international nature sanctuaries in border areas if the organisms in the areas are to be preserved.

The Xishuangbanna nature sanctuary group should be brought into an international conserving network which consists of parts of Laos. Myanmar and even including Northern Thailand and Vietnam because of the similarity of flora and fauna in the areas. Identical conservaiton regulations or laws are necessary for all the members in the area.

\section{2. 2 Conservation ex-situ}

The forms of conserving in public yards and in agroforestry systems, may be regarded as a component of conservation $e x$-situ. They are introduced as follows:

Conservation in public yards

The "green islands" refer to parks, campuses, memorial sites, public and private gardens, green areas of institutions as well as scenery sites, and other public yards. If organisms, usually plants, are introduced into these yards, they will be preserved very well while the yards will be beautified. It is easy to accept by citizens.

The total public yard areas are much more than the botanical garden areas in Xishuangbanna. The achievement of conservaiton in public yards will be quite impressive if appropriate organization, management, education, training and facilities are offered.

Conservation in agroforestry

Agroforestry has been practiced for thousands of years in China (Zou et al., 1990). Traditional agroforestry interacted with modern ones and promoted the numerous agroforestry systems in China. Agroforestry is now regarded as a promising trend in agricul- 
tural development because it can simultaneously create economic, ecological and social benefits (Xu, 1987). The potential of plants introduced into agroforestry systems will be vast. Different plants may be introduced into different systems and they will be reserved as well as used. This conservation method can be spread into indigenous societies.

\section{2.3 Traditional methods}

As mentioned above, the traditional conservation systems have existed for a long period and are easily accepted in Xishuangbanna society. Some major methods are described as follows:

- The Holy Hills of the Dai

The Holy Hills of the Dai became a part of traditional agroecosystem of Xishuangbanna about 1000 years ago (Pei, 1985a: Liiu, 1990). It originated from the Dai's ancient belief and respect for nature including forest, animals, plants and mountains. Holy Hills are an infportant visual element of modern Xishuangbanna landscape (Pei, 1986). There are approximately 400 Holy Hills in Xishuangbanna, each of them occupying some 10 100ha. Holy Hills are usually located near Dai villages and are covered with virgin forest becarse any human activity inside has been forbidden.

Higher plants and animals can be preserved in Holy Hills. Based on the latest report, there are at least 1500 animal and plant species living in Holy Hills (Liu, 1990). Therefore. Holy Hills are one of the most ideal locations to conserve biodiversity. In addition, for this conservaiton system, any extra input is not necessary at all except seeds (or seedlings) and animal babies which need to be protected and sustained until mature.

- Sangpabawa of Hani

Sangpabawa, or the traditional protected forest of Hani society, is a similar system to the Holy Hills of the Dai. But this system was established 120 years ago and originated from knowledge about reducing natural resources (Xu, 1991). It acts as both a source of water and keeper of biodiversity.

Similarly, the introduction of exotic organisms is considerable as Holy Hills are Because of the higher elevation of Sangpabawa (Hani perople usually live in mountains at an elevation of $800 \sim 1500 \mathrm{~m}$, and Dai live in basins and low areas with an elevation of $500 \sim 800 \mathrm{~m})$, it is necessary to select cold-resistant species.

1 - Buddhist temples of the Dai

Religion plays an important role in forest management and conservaiton. Wechakit (1989) has provided an outstanding description and analysis of Buddhism and the forests of Thailand. Buddhist monks protect and manage the organisms around their temples by treeplanting and wildlife-conservation. The similar thing occurs in Xishuangbanna Dai society since both Thai and Dai are Buddhist.

Usually, there is one Buddhist temple in a Dai village. The total number of temples reaches about 220. 58 plant species including trees, flowers and fruit were cultivated in Dai temple yards and the grounds nearby. Common species include: Ficus religiosa, Delonix regia, Tectona grandis, Corypha umbraculifera, Cassia siamea, Mangifera indica. Curcuma longa, Dendrobium spp.

The temple plants are usually conserved. The Dai villagers and exotic people never destroy these plants for the sake of religion. Plants which need to be conserved may be moved into temple yards.

- 60 . 


\section{- Yards of Xishuangbanna}

It has been proven that the yard is a traditional and sustainable agroforestry system, an important refuge of plant varieties, an important location of plant conservaiton and an important gene pool of living resorces (Pei, 1986; Cuc, 1990).

Yards can be observed throughout the whole prefecture of Xishuangbanna. 463 plant species and some animals are found in yards. In addition, all kinds of varieties of cultivated plants in yards are bred, preserved and utilized. As an important component of sustainable agroecosystems in Xishuangbanna, yards play an outstanding role socioeconomically and is regarded as a gene reservoir (Long, 1990). With help from the government and scientists, some endangered and rare plants can be moved into suitable yards to protect them from extinction.

\section{- Tea plantations of Jinuo}

The tea plantations of Jinuo nationality are similar to the natural forests structurally and ecologically. The forest canopy, which may be as high as 15 to 25 meters, provides the tea trees with a shade environment that enhances both the yield and the quality of tea produced. Trees are usually preserved as canopy by the tea plantations owners. The tea plantations generates some specific niches for a wide varieties and animals (Long et al. . 1993). Therefore, some organisms can be conserved in the traditional tea plantations of Jinuo.

\section{3 Strategies}

Government policy, financial support, scientific management, instruction and education are always significant in preserving biodiversity. Some managing and conserving successes have been achieved. The fact that the forest, vegetation and biodiversity has not been preserved very successfully has to be considered carefully despite the general strategies mentioned above having been adopted. In the author' s opinion, stressing the local people's factors and existing indigenous preservation practices is one of the most critical issues, especially in multi-ethnic areas like Xishuangbanna. Some concrete solutions for Xishuangbanna Nature Sanctuaries are explained as follows:

\section{3. 1 Residents living in and near nature sanctuaries}

Both encouragement and regulation must be adopted for managing and instructing the indigenous residents living in and near nature sanctuaries. It is necessary to help them to adopt the new approachs of productive structure and ultilization of natural resources rationally.

\section{3. 2 Replace wood with bamboo and spread fuelwood forest}

Bamboo huts and artificial fuelwood forest are traditional landscapes of Xishuagbanna. It would be good for preserving forest and biodiversity if these traditions are maintained and developed.

Bamboo grows fast and bamboo forest can be easily reestablished. If timber or wood is replaced with bamboo, the destruction of forest and biodiversity will be reduced. Fuelwood is the sole energy source for the villagers in Xishuangbanna. Villagers have to cut down trees or shrubs for their daily consumption. Cultivating fuelwood trees is a wonderful tradition of Xishuangbanna Dai people. The tree cultivated for fuel traditionally, known locally as gemaixili, is called Cassia siamica scientifically. It is a native tree species of Thailand and was introduced into Xishuangbanna for fuelwood about 400 years ago (Pei, 1985a). The practice of gemaixili fuelwood cultivation in Dai society

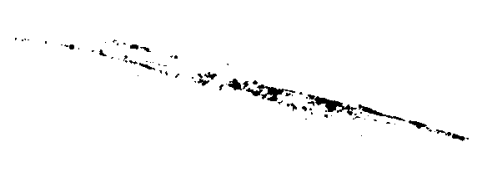


may spread to other ethnic groups as well as Han Chinese to meet their energy needs. Then the natural vegetation can be protected against deforestation for fuelwood.

\subsection{Local participation}

Many problems concerning biodiversity conservation are rather difficult to solve if the preservers do not include those who are volunteers (usually they are educated and foresighted persons) and from religious fields (eg. temples, animal or plant totems and Holy Hills). The exemplary role of volunteers will be effective in biodiversity conservation by their example and instruction since they live in local societies, if they are instructed and trained with both theory and practice by means of workshops on preserving biodiversity and natural vegetation.

\section{REFERENCES}

Cuc L T, K Gillogly. A T Rambo, (eds. ), 1990. Agroecosystems of the Midlands of Northern Vietnam. Occasional papers of the East-West Environment and Policy Institute, Honolulu: Paper 12: $138 \sim 151$

Liu Hongmao, 1990. Holy Hills and Plant Germplasm Conservation of Dai. In the 2nd International Congress of ethnobiology, Kunming (in Chinese)

Liu Long, (eds. ), 1989. Investigating Report on Land Economics of Xishuangbanna. Kunming: Yunnan People's Publish House (in Chinese)

Long Chunlin. 1990. Diversificaiton of Homegarden as A Sustainable Agroecosystem in Xishuangbanna. China. In SUAN V Symposium, Bandung, Indonesia

Long Chunlin. Wang Jieru, 1993. Forest Management and Biodiversity of Jinuo. Proceedings of Symposium on Biodiversity in Yunnan. Kunming: Yunnan Science and Technology Publish House, 189 $\sim 194$ (in Chinese)

Lu Rongyi, 1987. On the Status and Management of Nature Sanctuaries in Xishumgbanna. In the Conference on "Forests and Fields: Ecosystem Interaction in Tropical Asia", Xishuangbanna, China (in Chinese)

Pei Shengji, 1985a. Some Effects of the Dai People's Cultural Beliefs and Practices upon the Environment of Xishuangbanna, Yunnan. China, Cultural values and Human Ecology in Southeast Asia. University of Michigan, U.S. A.

Pei Shengji, 1985b. Preliminary Survey of Swidden Cultivation in the Tropical area of Yunnan, China, from An Ethnoecology Point of View. In Workshop on Rural Ecosystem Research, Nanjing. China

Pei Shengji, 1986. Traditional Agroecosystems in Xishuangbanna, Yunnan. China. In SUANIV Symposium, Chiangmai, Thailand

Rambo A T, P E Sajise, (eds.), 1984. An Introduction to Human Ecology Research on Agricultural Systems in Southeast Asia. Los Banos (the Philippines): University Publications Program

Wechakit D, 1989. Buddhist Monks and Social Forestry in Thailand. Occasional papers of the EastWest Environment and Policy Institute. Honolulu: Hawaii, U. S. A.

Xu Jianchu, 1991. Study on Rural Agroecosystems of Mengsong Mountains. In Academic Conference of Kunming Institute of Botany. Academia Sinica, Kunming, China

Xu Zaifu, Yu Pinghua, Pei Shengji. 1982. Research on Reservation $f$ Germplasm Resources of tropical Plant in Xishuangbanna. In Collected Research Papers on the Tropical Botany. Kunming: Yunnan People's Publish House, 7 15 (in Chinese)

Xu Zaifu, 1987. From Shifting Cultivation to Agroforestry, A Tendency of Agricultural Development in the Mountain Areas of Yunnan Tropics. In the Conference on "Forests and Fields: Ecosystem Interaction in Tropical Asia", Xishungbanna, China

Zou Xiaomin, R L Sanford, 1990. Agroforestry Systems in China: A Survey and Classification. Agroforestry Systems. 11: 85 94

- 62 • 